\title{
Marangoni Convection Induced Ripple on Grazing Incidence Liquid Metal Mirror (GILMM) Used for Laser Inertial Fusion Energy
}

R.W. Moir

August 27, 2001

U.S. Department of Energy

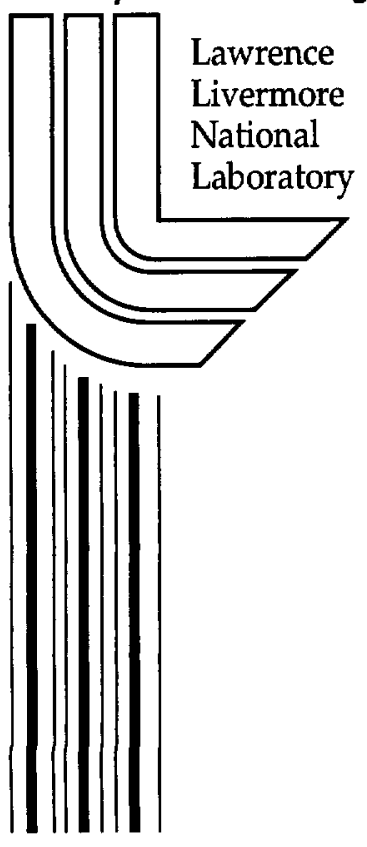




\section{DISCLAIMER}

This document was prepared as an account of work sponsored by an agency of the United States Government. Neither the United States Government nor the University of California nor any of their employees, makes any warranty, express or implied, or assumes any legal liability or responsibility for the accuracy, completeness, or usefulness of any information, apparatus, product, or process disclosed, or represents that its use would not infringe privately owned rights. Reference herein to any specific commercial product, process, or service by trade name, trademark, manufacturer, or otherwise, does not necessarily constitute or imply its endorsement, recommendation, or favoring by the United States Government or the University of California. The views and opinions of authors expressed herein do not necessarily state or reflect those of the United States Government or the University of California, and shall not be used for advertising or product endorsement purposes.

This is a preprint of a paper intended for publication in a journal or proceedings. Since changes may be made before publication, this preprint is made available with the understanding that it will not be cited or reproduced without the permission of the author.

This report has been reproduced directly from the best available copy.

Available electronically at http://www.doe.gov/bridge

Available for a processing fee to U.S. Department of Energy

and its contractors in paper from

U.S. Department of Energy

Office of Scientific and Technical Information

P.O. Box 62

Oak Ridge, TN 37831-0062

Telephone: (865) 576-8401

Facsimile: (865) 576-5728

E-mail: reports@adonis.osti.gov

Available for the sale to the public from

U.S. Department of Commerce

National Technical Information Service

5285 Port Royal Road

Springfield, VA 22161

Telephone: (800) 553-6847

Facsimile: (703) 605-6900

E-mail: orders@ntis.fedworld.gov

Online ordering: http://www.ntis.gov/ordering.htm

OR

Lawrence Livermore National Laboratory

Technical Information Department's Digital Library

http://www.llnl.gov/tid/Library.html 


\title{
Marangoni convection induced ripple on grazing incidence liquid metal mirror (GILMM) used for laser inertial fusion energy
}

\author{
R. W. Moir
}

August 27, 2001

\begin{abstract}
A spatial variation of temperature in the sodium film on the surface of the grazing incidence liquid metal mirror (GILMM) will give rise to convection due to the temperature dependent variation in surface tension. This is called thermal capillary convection or the Marangoni effect and causes the surface to have ripples or waves. This note estimates the magnitude of this effect and finds, with care, design parameters can be chosen to make the resulting ripples sufficiently small so that a laser beam can be focused on a target of $1 / 4 \mathrm{~mm}$ spot size at $30 \mathrm{~m}$ distance, for example. Smaller spot sizes are discussed.
\end{abstract}

\section{Introduction}

An inertial fusion energy (IFE) power plant that uses lasers will have final optics exposed directly to the microexplosion. Grazing incidence metal mirrors have been proposed for the final optics. Even more robust would be liquid metal mirrors because liquids can recover after each burst of neutrons, $x$-rays and debris coming from the exploding target. The question then becomes, "can the liquid surface be maintained sufficiently smooth to allow an adequately small spot size?" The spot size is made up of laser pointing or jitter considered here as well as diffraction spreading, optics aberrations and other effects. The objective of this note is to address that question. The grazing incidence liquid metal mirror (GILMM) arrangement is shown in Fig. 1 and described in Ref. 1.

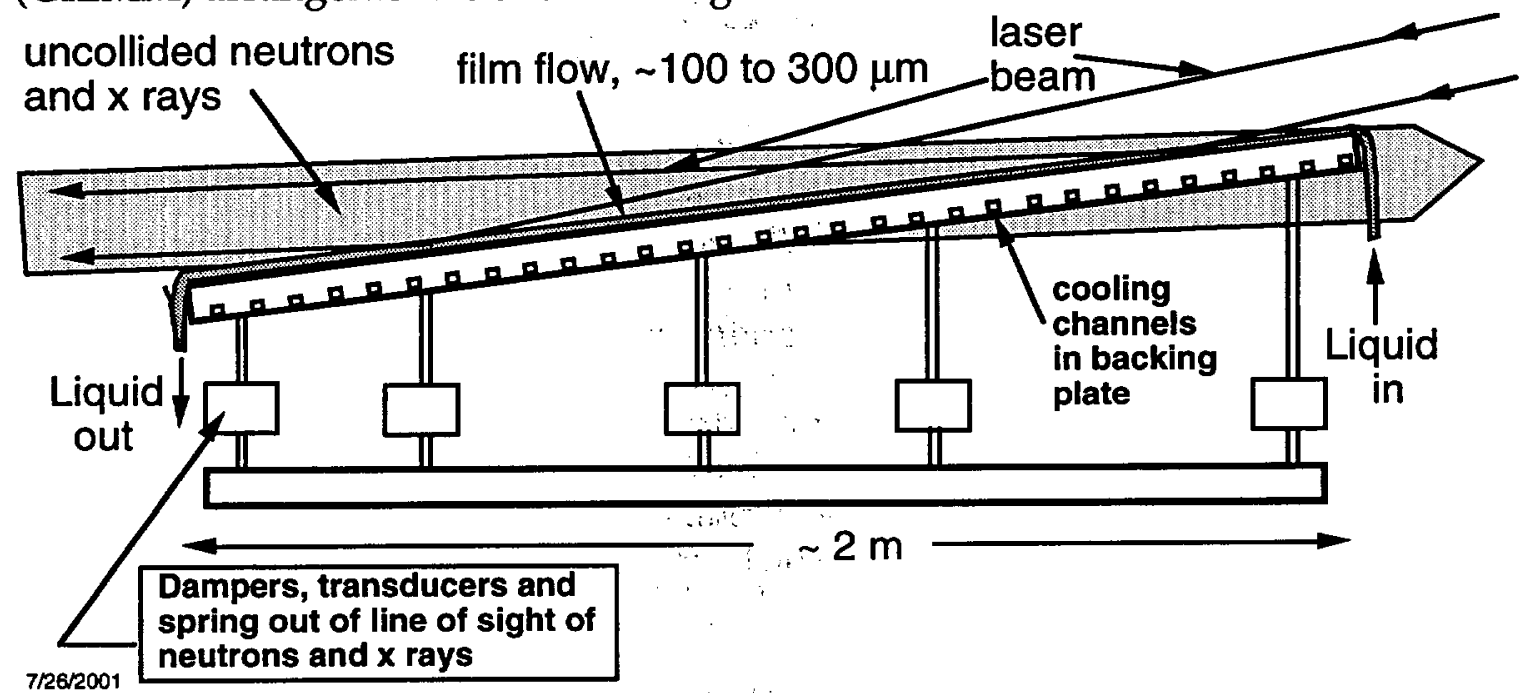

Fig. 1. Grazing incidence liquid metal mirror. 
Ideally, the thin film of liquid flowing down the inclined plane will be stable and perfectly smooth forming a good reflecting surface. Viscous effects damp out disturbances for a sufficiently thin film. However, disturbances can be caused by a number of effects resulting in a ripple shown in Fig. 2.

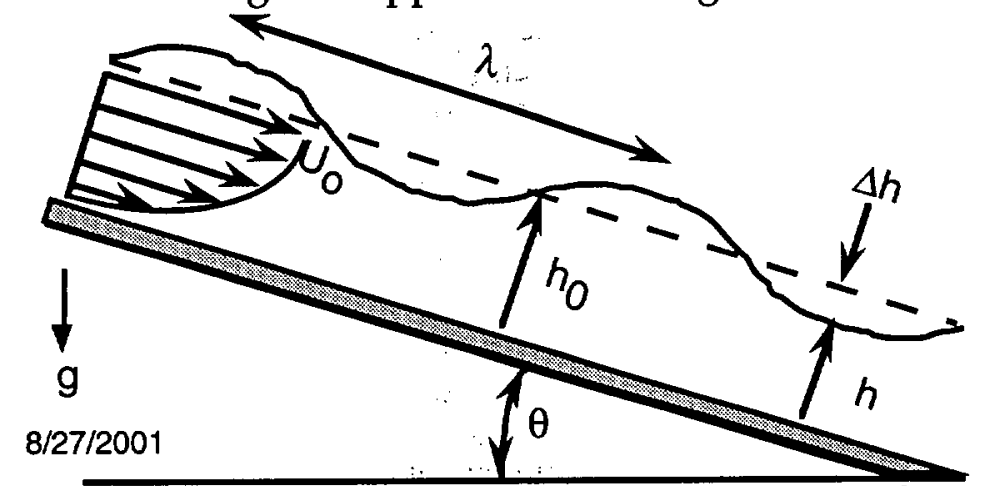

Fig. 2. Ripple shown on the film due to disturbances of any kind.

In reality there are disturbances induced by prior laser pulses incident on the liquid surface. These disturbances may be incompletely damped in the interpulse time of $\sim 0.1 \mathrm{~s}$. The backing plate surface will not be perfectly smooth and its temperature will have small variations.due to variations in the intensity of the prior laser pulses or due to the periodicity of the cooling channels near the back of the plate as shown in Fig. 1. We will leave most of these effects to future studies and treat the effect of the periodicity of the cooling channel.

A tractable problem is to estimate the ripple due to temperature variations in a thin film on a horizontal surface as shown in Fig. 3. The idea is to assume phenomena much the same will be superimposed on the flow down a plane.

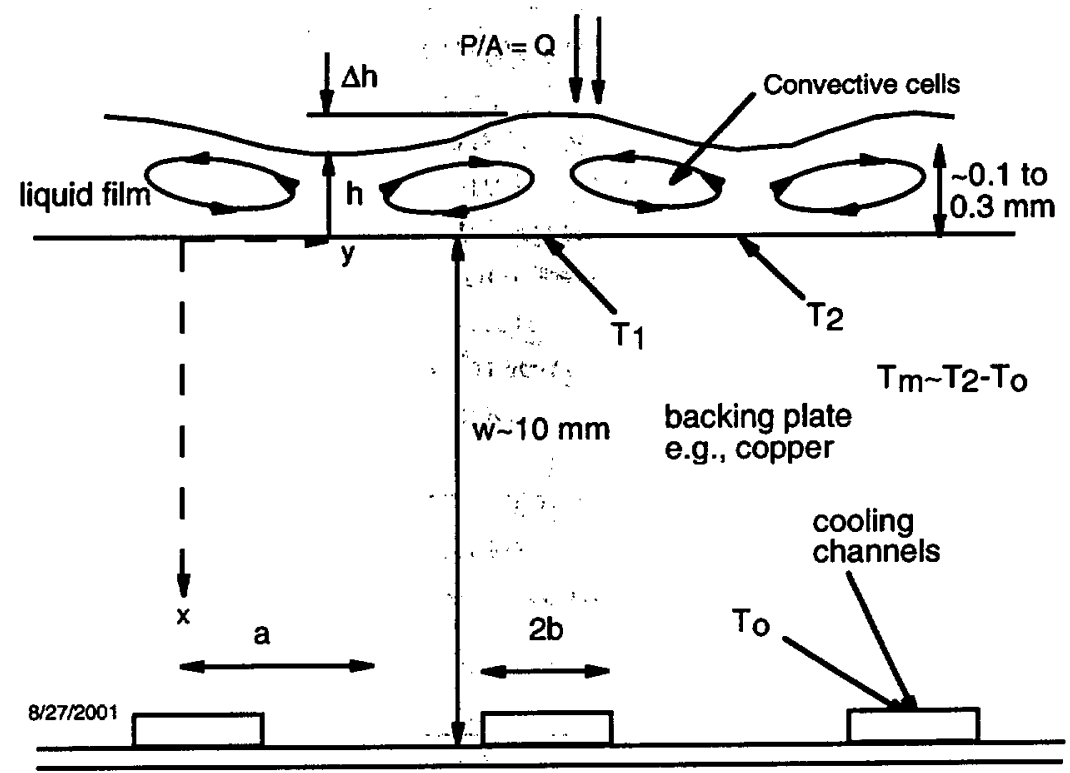

Fig. 3. Geometry of the backing plate for thermal management to minimize the Marangoni convection for GILMM. The liquid film is shown enlarged to emphasize the ripple and convective cells. 


\section{Estimate of convection induced surface ripple}

Steady flows are set up by variation in surface tension in a thin liquid film. The surface tension pulls the surface layer towards the colder regions. This convection drags the bulk by viscous drag until the liquid piles up so much that gravity driven convection just balances this flow. The thickness, $h$, is given in Ref. 2 for a thin film with small amplitude disturbances.

$$
\mathrm{h}^{2}=\mathrm{h}_{\mathrm{o}}^{2}\left(\frac{\rho_{o}}{\rho}\right)^{\frac{3}{4}}+\frac{3\left(\sigma-\sigma_{o}\right)}{\rho g}
$$

Where $\Delta h=$ variation in thickness, $h$ when $\sigma$ the surface tension and $\rho$ the density are varied from there reference values.

For $\Delta \mathrm{h}<<\mathrm{h}$ and $\mathrm{h}<<\mathrm{a}$.

Values of surface tension, $\sigma$, is given from Ref. 3 for sodium, whose melt temperature is $98^{\circ} \mathrm{C}$. The density, $\rho$, of sodium is $970 \mathrm{~kg} / \mathrm{m}^{3}$.

$$
\begin{array}{rlrl}
\sigma & =0.2064 \mathrm{~N} / \mathrm{m} ; \quad T=100^{\circ} \mathrm{C} & \text { Ref. 3, Liquid metals handbook } \\
& =0.1995 \mathrm{~N} / \mathrm{m} ; \quad T=250^{\circ} \mathrm{C} & \\
\sigma & =0.2064 \cdot(1-\alpha \Delta T) \mathrm{N} / \mathrm{m} & \\
\Delta T & =T-100^{\circ} \mathrm{C} & & \\
\alpha & =0.000223 & &
\end{array}
$$

From Ref. 3 more detailed data, see Fig. 4

$$
\alpha=0.000506
$$

We will use the larger value of $\alpha$.

$$
\begin{aligned}
& \Delta h=h-h_{0} \\
& \Delta h=\frac{3 \sigma_{o} \alpha \Delta T}{2 h \rho g}=\frac{3 \cdot 0.2064 \cdot 0.000506 \cdot \Delta T}{2 h \cdot 970 \cdot 9.8}=1.65 \cdot 10^{-8} \cdot \frac{\Delta T}{h}
\end{aligned}
$$

A typical film might be 0.1 to $0.3 \mathrm{~mm}$ thick. We will use the lower value for our estimates. Then

$$
\Delta h=1.65 \cdot 10^{-4} \Delta T
$$


The film thickness variation depends on temperature but not on distance directly. In a distance of $1 / 4$ wavelength $(\lambda=2 a)$, the temperature varies by $\pm \Delta T$ and $\Delta \mathrm{h}= \pm 1.65 \times 10^{-4} \Delta \mathrm{T}$ in the example above.

Surface tension for sodium

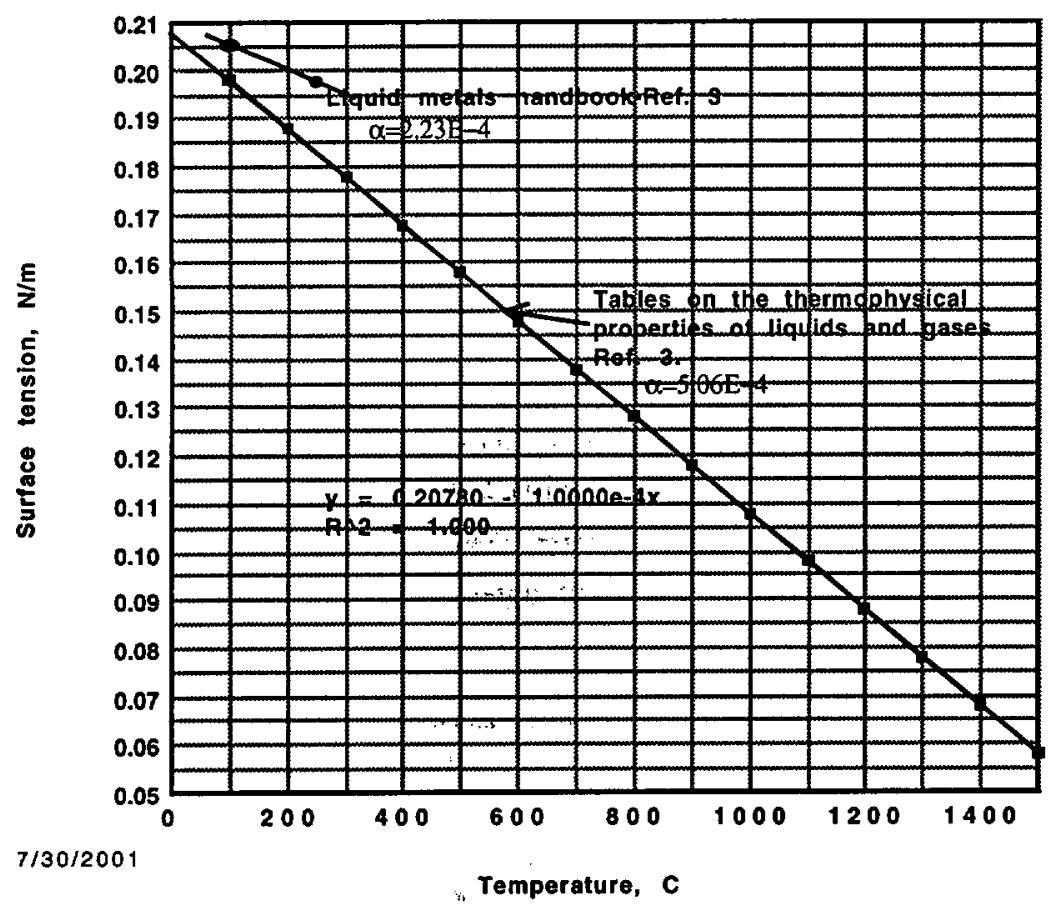

Fig. 4. Data on surface tension for sodium

\section{Allowed surface ripple}

In Ref. 1 we show a sinusoidal surface ripple of $\pm \Delta$ h over a wavelength, $\lambda$, will cause the surface to ripple in angle by $\pm 2 \pi \Delta \mathrm{h} / \lambda$, which will deflect the laser beam by twice this amount. An allowed angle might be $\pm 0.25 \mathrm{~mm} / 30 \mathrm{~m}= \pm 0.83 \times 10^{-5}$ radians, based on targets typical dimensions being $\sim 2.5 \mathrm{~mm}$.

$\frac{ \pm 4 \pi \Delta h}{\lambda}=0.83 \times 10^{-5}$

As an example we assume:

$\lambda=10 \mathrm{~mm}$

$\Delta h= \pm 6.6 n m$

$\Delta T= \pm 4.0 \times 10^{-5}{ }^{0} \mathrm{C}$

In a distance of $10 \mathrm{~mm}$ between cooling channels $(\lambda=10 \mathrm{~mm}=2 \mathrm{a})$ we can tolerate $\Delta \mathrm{h}= \pm 6.6 \mathrm{~nm}$. This requires $\Delta \mathrm{T}= \pm 4.0 \times 10^{-5}{ }^{\circ} \mathrm{C}$. In a distance of $100 \mathrm{~mm}$ the temperature difference can be $\pm 4.0 \times 10^{-4}{ }^{\circ} \mathrm{C}$ and over $1 \mathrm{~m}$ it can be $\pm 4.0 \times 10^{-3}{ }^{\circ} \mathrm{C}$. 
The flow speed down the plane is typically $10 \mathrm{~mm} / \mathrm{s}$, so that in $1 / 6 \mathrm{~s}$ the liquid has moved $\sim 1 \mathrm{~mm}$ between shots. This will have only modest temperature smoothing effects.

To achieve the above small temperature variations along the front of the plate will require good thermal management. Can parameters in Fig. 3 be chosen to obtain these small temperature variation? The spacing of the cooling channels will have to be small, $a / w<1$ and $b / a$ approaches 1 . The cooling system design requires a standard heat transfer analysis, which is covered in the next section.

A way to achieve smaller contribution to the spot size would be to go to shorter focal distance than the $30 \mathrm{~m}$ example and films flowing down only slightly inclined planes so the film could be several times thicker than the example in Eq. 8 . These combined effects might allow a pointing jitter of $\pm 25 \mu \mathrm{m}$.

\section{Heat transfer analysis}

The temperature of the film will be near the temperature of the surface of the backing plate at the time of the next shot. The distance a heat pulse travels, $l$, or diffuses is given as

$$
l^{2}=\alpha \tau
$$

where $\tau$ is the interpulse time and the thermal diffusivity, $\alpha$, is

$$
\alpha_{N a}=\frac{k}{\rho C}=\frac{89.7 \mathrm{~W} / \mathrm{mK}}{927 \mathrm{~kg} / \mathrm{m}^{3} \cdot 1386 \mathrm{~J} / \mathrm{kgK}}=6.98 \times 10^{-5} \mathrm{~m}^{2} / \mathrm{s}
$$

where $k$ is thermal conductivity, $\rho$ is density and $C$ is heat capacity.

$l=3.4 \mathrm{~mm}$ for $\tau=1 / 6 \mathrm{~s}$.

During a $10 \mathrm{~ns}$ pulse the heat has diffused only $0.8 \mu \mathrm{m}$ but in $1 / 6 \mathrm{~s}$ the film should be at the temperature of the front of the plate because the thermal diffusion distance is far larger than the film thickness. The temperature of the film will equilibrate with the temperature of the plate after a shot.

For the copper backing plate the thermal diffusivity is

$$
\begin{aligned}
& \alpha_{C u}=\frac{k}{\rho C}=\frac{380 \mathrm{~W} / \mathrm{mK}}{8900 \mathrm{~kg} / \mathrm{m}^{3} \cdot 385.2 \mathrm{~J} / \mathrm{kgK}}=1.1 \times 10^{-4} \mathrm{~m}^{2} / \mathrm{s} \\
& l=\sqrt{1.8474 \times 10^{-5}}=4.3 \mathrm{~mm} \text { for } \tau=1 / 6 \mathrm{~s} .
\end{aligned}
$$

The backing plate is likely to be 10 to $20 \mathrm{~mm}$ thick, which is much larger than the $4 \mathrm{~mm}$ thermal diffusion distance in copper. This means the temperature at the front of the plate is due to the energy deposited by many laser pulses and 
justifies the assumption of steady heat flow to determine the temperature of the film. Also the variation from shot to shot is smoothed out as well. Other backing plate materials such as aluminum or stainless steel might be advantageous. Stainless steel would have a longer thermal diffusivity distance and therefore smooth out the pulses for past laser shots more. Aluminum would be lighter.

The reflectivity of the sodium film for $1 / 3 \mu \mathrm{m}$ light is calculated to be $99.5 \%{ }^{1}$. For a copper plate $1 \mathrm{~cm}$ thick and a $6 \mathrm{~Hz}$ pulse rate with $5 \mathrm{~J} / \mathrm{cm}^{2}$ laser and 0.025 $\mathrm{J} / \mathrm{cm}^{2}$ absorbed, we get a surface temperature rise of the front of the plate over that of the back of the plate, $T_{m}$. Again, $T_{m}$ is the average temperature difference from the front to the back of the plate. The plate thickness is $w$.

$$
\frac{P}{A}=Q=\frac{0.025 \mathrm{~J} / \mathrm{cm}^{2}}{\frac{1}{6} \mathrm{~s}}=0.15 \mathrm{~W} / \mathrm{cm}^{2}
$$

where $\mathrm{P} / \mathrm{A}$ is the absorbed power per unit area on the film

$$
\begin{aligned}
& k=3.8 \frac{\mathrm{W}}{\mathrm{cmK}}=\text { thermal conductivity for copper } \\
& \frac{P}{A}=k \frac{T_{m}}{w}=Q \\
& T_{m}=\frac{1 \mathrm{~cm} \cdot 0.025 \mathrm{~J} / \mathrm{cm}^{2}}{\frac{1}{6} \mathrm{~s} \cdot 3.8 \frac{\mathrm{W}}{\mathrm{cmK}}}=0.0395^{\circ} \mathrm{C}
\end{aligned}
$$

The temperature across a $100 \mu \mathrm{m}$ sodium film on average will be $1.7 \times 10^{-3}{ }^{\circ} \mathrm{C}$, for this example. If the film happens to be thicker at the time of the next shot, then its temperature will increase proportionally and Marangoni convection will tend to reduce this thickness. This stabilizing effect is left for future analysis.

\section{Temperature variation due to variations in laser power}

Since the allowed temperature variation along the surface transverse to the channel direction $\left(4.0 \times 10^{-5}{ }^{\circ} \mathrm{C}\right.$ for $10 \mathrm{~mm}$ spacing) is very small compared to the temperature difference from the film to the back of the plate $\left(0.0395^{\circ} \mathrm{C}\right)$, any spatial variation in incident power or plate thickness will be important. For example, if the laser power varies by $0.1 \%$ over a distance of $10 \mathrm{~mm}$, then there will be a $\Delta \mathrm{T}$ of $4 \times 10^{-5}{ }^{\circ} \mathrm{C}$, which is just the allowed value (see Eq. 10). Over a distance of $100 \mathrm{~mm}$, the laser can vary in power by $1 \%$ and by $10 \%$ over $1 \mathrm{~m}$. In order to hit a spot size ten times smaller, $\pm 25 \mu \mathrm{m}$, will require laser power variations ten times smaller than those of our example

\section{Temperature variation along channel due to coolant heat up}


There will be a temperature variation along the cooling channels due to the coolant warming up from the laser heating. Assume the coolant is sodium in cooling channels equivalent to $4 \mathrm{~mm}$ thick layer flowing at $1 \mathrm{~m} / \mathrm{s}$. The temperature rise of the coolant and therefore of the front of the plate is:

$$
\begin{aligned}
& \frac{d T}{d t}=\frac{Q \tau^{-1}}{\delta \rho C}=\frac{0.025 \mathrm{~J} / \mathrm{cm}^{2} \cdot 10^{4} \mathrm{~cm}^{2} / \mathrm{m}^{2} \cdot 6 \mathrm{~Hz}}{0.004 \mathrm{~m} \cdot 927 \mathrm{~kg} / \mathrm{m}^{3} \cdot 1386 \mathrm{~J} / \mathrm{kgK}}=0.29^{\circ} \mathrm{C} / \mathrm{s} \\
& \frac{d T}{d z}=\frac{d T}{d z} \frac{d z}{d t}=0.29{ }^{\circ} \mathrm{C} / \mathrm{s} \cdot 1 \mathrm{~m} / \mathrm{s}=0.29^{\circ} \mathrm{C} / \mathrm{m}
\end{aligned}
$$

This temperature rise is 70 times that of $\pm 4.0 \times 10^{-3}{ }^{\circ} \mathrm{C}$ quoted above for $1 \mathrm{~m}$. If the temperature rise is perfectly uniform along the direction of flow, the convective cell will give rise to a layer thickening uniformly along the flow. It is the nonuniformity along the cooling direction that would give rise to a ripple. Clearly, many aspects of thermal management will be important.

\section{Fourier analysis of surface temperature variation due to cooling channels}

Since small variations of temperature on the film will cause convection generated ripples it is important to minimize this temperature variation. Therefore we will solve the heat conduction problem by Fourier analysis following a similar problem solved by VanSant (Ref. 4). The geometry is shown in Fig. 3. We assume the depth of the cooling channels in the $x$ direction are negligible compared to $\mathrm{w}$, the backing plate thickness. The simplified geometry is shown in Fig. 5 and the boundary conditions are given below:

1. $\partial \mathrm{T}(\mathrm{x}, 0) / \partial \mathrm{y}=0$

2. $\partial \mathrm{T}(\mathrm{x}, \mathrm{a}) / \partial \mathrm{y}=0$

3. $\mathrm{k} \partial \mathrm{T}(0, \mathrm{y}) / \partial \mathrm{x}=-\mathrm{Q}=-\mathrm{P} / \mathrm{A}$

4. $T(w, y)=T_{0} \quad(0<y<b)$

$$
\partial \mathrm{T}(\mathrm{w}, \mathrm{y}) / \partial \mathrm{x}=0 \quad(\mathrm{~b}<\mathrm{y}<\mathrm{a})
$$

Beginning with Laplace's equation in two:dimensions $\left(\nabla^{2} T(x, y)=0\right)$ and using the separation of variable technique, the following can be obtained:

$$
T(x, y)=\left[C_{1} \cosh (\lambda x)+C_{2} \sinh (\lambda x)\right] \cdot\left[C_{3} \cos (\lambda y)+C_{4} \sin (\lambda y)\right]
$$

When the first boundary condition is applied to Eq. (25), the result is

$$
\mathrm{C}_{4}=0
$$

If the second boundary condition is next applied to Eq. (25), one obtains

$$
\operatorname{Sin}(\lambda a)=0, \quad \lambda_{n}=n \pi / a, n=0,1,2, \ldots \ldots
$$




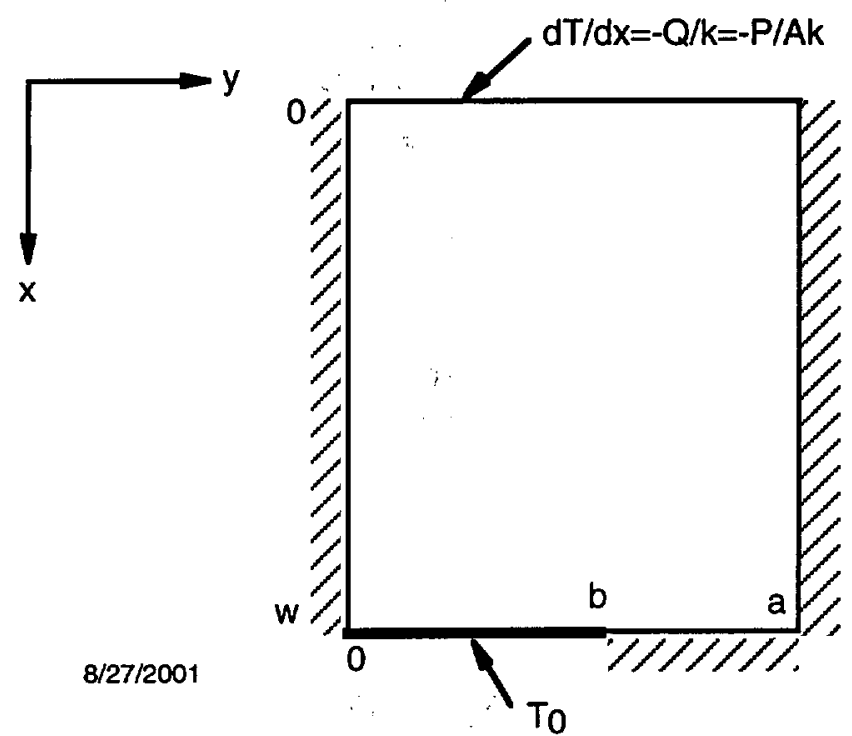

Fig. 5. Simplified geometry for the Fourier analysis.

The equation for temperature can now be rewritten as

$T(x, y)=\sum_{n=0}^{\infty}\left[A_{n} \cosh (n \pi x / a)+B_{n} \sinh (n \pi x / a)\right] \cos (n \pi y / a)$

The third boundary condition requires that

$k \frac{\partial T(0, y)}{\partial x}=-Q$

$k \sum_{n=0}^{\infty}\left[A_{n} \frac{n \pi}{a} \sinh (n \pi x / a)+\frac{n \pi}{a} B_{n} \cosh (n \pi x / a)\right] \cos (n \pi y / a)=-Q$

$k \sum_{n=0}^{\infty}\left[\frac{n \pi}{a} B_{n}\right] \cos (n \pi y / a)=-Q$

$\int_{0}^{a} k \frac{n \pi}{a} B_{n} \cos ^{2}(n \pi y / a) d y=-Q \int_{0}^{a} \cos (n \pi y / a) d y$

$k \frac{n \pi}{a} B_{n} \frac{a}{2}=-Q \frac{a}{n \pi}[\sin (n \pi a)-\sin (0)]=0$

$B_{n}=0, n>0$

The integral in Eq. 25 is now done for $n=0$.

$k\left[\frac{n \pi}{a} B_{n}\right] a=-Q a, \quad n=0$ 


$$
B_{n}=\frac{-Q a}{n \pi k}, \quad n=0
$$

The second term is evaluated by taking the limit as $\mathrm{n}$ approaches zero.

$$
B_{n} \sinh (n \pi x / a)=-Q \frac{x}{k}, \quad n=0
$$

Eq. 28 is now rewritten.

$$
T(x, y)=\sum_{n=0}^{\infty}\left[A_{n} \cosh (n \pi x / a) \cdot \cos (n \pi y / a)\right]-\frac{Q x}{k}
$$

The fourth boundary condition requires that

$T(w, y)=T_{0}, \quad 0<y<b$

and

$$
k \frac{\partial T(w, y)}{\partial x}=0, \quad b<y<a
$$

These boundary conditions are mixed value and derivative conditions, which gives us trouble. We know that the average heat flux by conservation of energy is $\mathrm{Qa} / \mathrm{b}$ between 0 and $\mathrm{b}$. If, we take the value as constant rather than the average then the boundary condition is a derivative condition all along this boundary and this altered problem becomes tractable.

$$
\begin{aligned}
& k \frac{\partial T(w, y)}{\partial x}=Q a / b, \quad 0<y<b \\
& \int_{0}^{a}\left[A_{n} \frac{n \pi}{a} \sinh (n \pi w / a) \cdot \cos ^{2}(n \pi y / a)\right] d y-\int_{0}^{a} \frac{Q}{k} \cos (n \pi y / a) d y=-\int_{0}^{b} \frac{Q}{k} \frac{a}{b} \cos (n \pi y / a) d y \\
& A_{n}=\frac{-\frac{Q a}{k b} \int_{0}^{b} \cos (n \pi y / a) d y}{\frac{n \pi}{a} \sinh (n \pi w / a) \int_{0}^{a}\left[\cdot \cos ^{2}(n \pi y / a)\right] d y} \\
& A_{n}=-2 \frac{Q a^{2}}{k b}\left(\frac{1}{n \pi}\right)^{2} \frac{\sin \left(n \pi \frac{b}{a}\right)}{\sinh (n \pi w / a)}
\end{aligned}
$$


Eq. (31) now becomes

$T(x, y)=A_{0}+\sum_{n=1}^{\infty}\left[A_{n} \cosh (n \pi x / a) \cdot \cos (n \pi y / a)\right]-\frac{Q x}{k}$

When $\mathrm{x}=\mathrm{w}, \mathrm{a}=\mathrm{b}$, then $\mathrm{A}_{0}=0$ and $\mathrm{T}=\mathrm{T}_{0}$.

$T_{0}=A_{0}-\frac{Q w}{k}$

It is not clear what the value of temperature is along the boundary, $x=w, 0<y<b$. However, with this condition, the temperature then becomes

$$
T(x, y)=T_{0}+\frac{Q(w-x)}{k}+\sum_{n=1}^{\infty}\left[A_{n} \cosh (n \pi x / a) \cdot \cos (n \pi y / a)\right]
$$

The temperature variation in the film is given as

$$
\Delta T=T(0, a)-T(0,0)=\sum_{n=1}^{\infty}\left[A_{n} \cdot(-1)^{n}\right]-\sum_{n=1}^{\infty}\left[A_{n}\right]=2 \sum_{n>0, o d d}^{\infty} A_{n}
$$

The fractional temperature variation is given as

$$
\frac{\Delta T}{T_{m}}=\frac{T(0, a)-T(0,0)}{Q w / k}=\frac{4 a^{2}}{b w} \sum_{n>0, \text { odd }}^{\infty} \frac{1}{(n \pi)^{2}} \frac{\sin (n \pi b / a)}{\sinh (n \pi w / a)}
$$

where $T_{m}$ is nominally the temperature difference from front to back of the plate. The results in the above two equations under estimate the temperature variation somewhat due to the altered boundary condition of Eq. 41. The fractional temperature variation, $\Delta T / T_{m}$, is plotted in Fig. 6 for typical cooling system parameters defined in Fig. 3 and 5.

To check the accuracy of the Fourier analysis, Laplace's equation was solved numerically using the relaxation method (see Ref. 5) for the conditions shown in Fig. 5. with the boundary conditions of Eq. 17. The results were within a few percent of the values given in Fig. 6

We can now find by trial and error typical parameters that satisfy the small thermal convection induced ripple. $T_{m}=0.0395^{\circ} \mathrm{C}$ from the example of Eq. (18) earlier. In a distance of $10 \mathrm{~mm}$ between cooling channels we can tolerate $\Delta \mathrm{h}= \pm 6.6$ $\mathrm{nm}$, in order to have a spot size of $\pm .0 .25 \mathrm{~mm}$ (see Eq. $9 \& 10$ ). This requires $\Delta \mathrm{T}= \pm 4.0 \times 10^{-5}{ }^{\circ} \mathrm{C}$. Thus the required $\Delta \mathrm{T} / \mathrm{T}_{\mathrm{m}}= \pm 4.0 \times 10^{-5}{ }^{\circ} \mathrm{C}$. $/ 0.0395{ }^{\circ} \mathrm{C}= \pm 1.01 \times 10^{-3}$. The parameter $a=10 \mathrm{~mm}$, for $w=10 \mathrm{~mm}, w / a=1$. This gives $b / a>0.95$, i.e., no solution. A better set of parameters might be $w=10 \mathrm{~mm}, \mathrm{a}=5 \mathrm{~mm}$, the required $\Delta \mathrm{T} / \mathrm{T}_{\mathrm{m}}= \pm 2.0 \times 10^{-5}{ }^{\circ} \mathrm{C} / 0.0395^{\circ} \mathrm{C}= \pm 5.56 \times 10^{-4}, \mathrm{~b} / \mathrm{a}=0.8$, which is close to acceptable. For $\mathrm{w}=15 \mathrm{~mm}, \mathrm{a}=6.5 \mathrm{~mm}$, the required $\Delta \mathrm{T} / \mathrm{T}_{\mathrm{m}}= \pm 2.6 \times 10^{-5}{ }^{\circ} \mathrm{C} / 0.059$ 


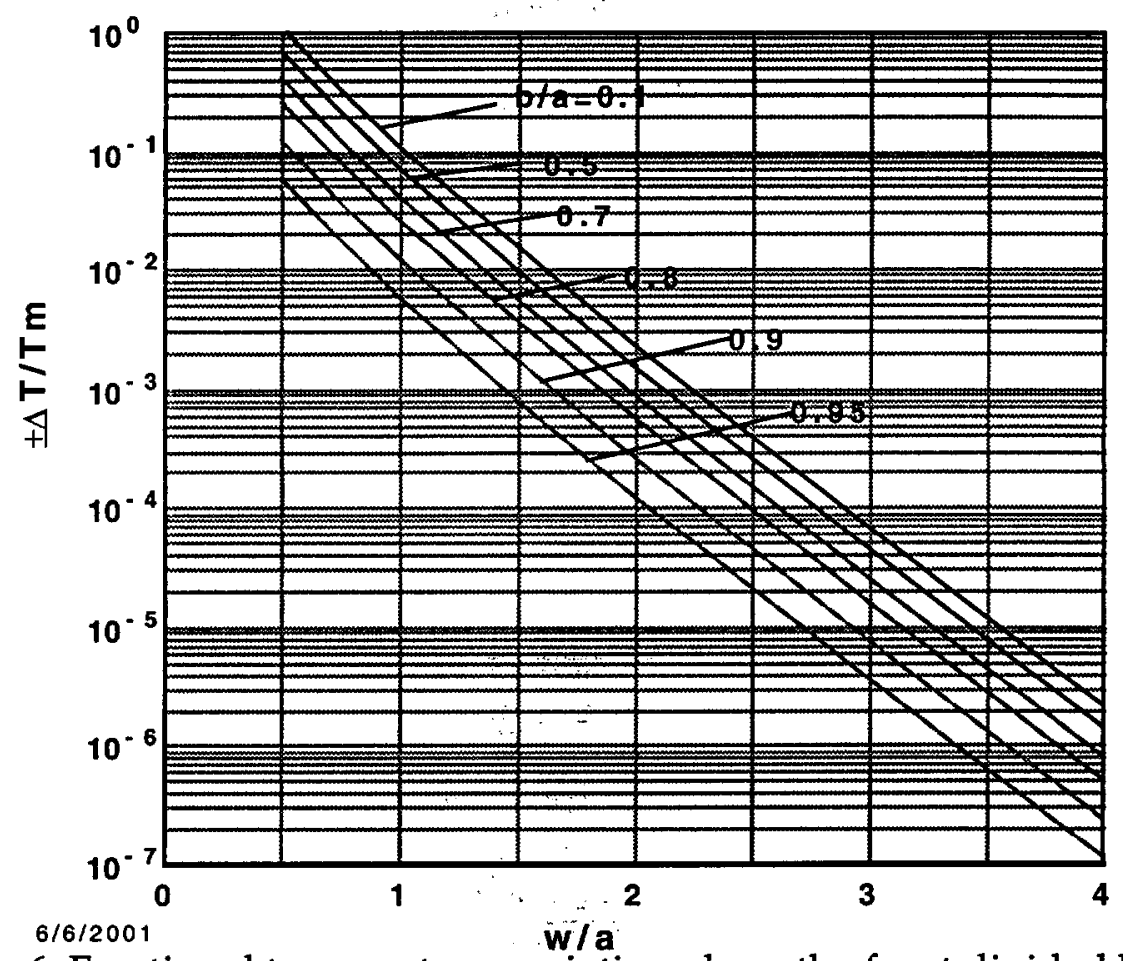

Fig. 6. Fractional temperature variation along the front divided by the temperature difference front to back.

${ }^{\circ} \mathrm{C}= \pm 4.4 \times 10^{-4}, \mathrm{~b} / \mathrm{a}=0.5$, which seems like a practical set of cooling channel parameters. If we need to hit a spot size of $\pm 25 \mu \mathrm{m}$, parameters from Fig. 6 can easily be chosen to achieve this result.

Apparently a sufficiently small temperature variation due to the discrete periodic cooling channels can be obtained; however the fact that we require less than a variation of $\pm 4 \times 10^{-5}{ }^{\circ} \mathrm{C}$ over distances of order $10 \mathrm{~mm}$ should put us on alert for effects not included.

\section{Conclusions}

In general, thermal management will be an important subject for successful application of the GILMM concept. As an example of our results, for a $100 \mu \mathrm{m}$ sodium film we found small enough ripple for a backing plate $15 \mathrm{~mm}$ thick and cooling channels spaced $7 \mathrm{~mm}$ apart of $4 \mathrm{~mm}$ width. This allowed the jitter portion of spot size for hitting a target $\pm 1 / 4 \mathrm{~mm}$ at $30 \mathrm{~m}$. If a smaller jitter is required, such as $\pm 25 \mu \mathrm{m}$, the ripple due to all effects must be ten times smaller than the examples used in this report. The temperature variation due to the cooling channels can be made small enough by design choices, however, other requirements such as laser spatial uniformity might be difficult to achieve and they will need further study. 


\section{Acknowledgements}

Extensive discussions with W. L. Barr are appreciated. Also, thanks are due to Lee Pittenger and Charles Landram for discussions on Fourier analysis techniques. This work was performed under the auspices of the U.S. Department of Energy by University of California Lawrence Livermore National Laboratory under contract No. W-7405-Eng-48.

\section{References}

1. R. W. Moir, "Grazing incidence liquid metal mirrors (GILMM) for radiation hardened final optics for laser inertial fusion energy power plants," Fusion Engineering and Design 51-52 (2000) 1123-1130.

2. L. D. Landau and E. M. Lifshitz, Fluid Mechanics, Second Edition, Volume 6 of Course if Theoretical Physics, Second English Edition, Revised, Translated from the Russian by J. B. Sykes and W. H Reid, Pergamon Press, Oxford, (1987) p244.

3. Liquid metals handbook, $3^{\text {rd }}$ edition; $\mathrm{p} 41$, C. B. Jackson, Washington DC USGPO (1955)

and Tables on the thermophysical properties of liquids and gases, Second edition by N. B. Vargaftik, Halsted Press Book, Wiley and sons, New York, p 108 (1975).

4. James H. VanSant, "Temperature of a flat plate having alternating adiabatic and constant heat flux strips on one side," Lawrence Livermore Laboratory, Livermore, CA, UCRL 7990 (1964).

5. W. L. Barr, private communications, June 2001. 